\title{
Causal beliefs about obesity and associated health behaviors: results from a population-based survey
}

Catharine Wang ${ }^{1 *}$, Elliot J Coups ${ }^{2,3}$

\begin{abstract}
Background: Several genetic variants are associated with obesity risk. Promoting the notion of genes as a cause for obesity may increase genetically deterministic beliefs and decrease motivation to engage in healthy lifestyle behaviors. Little is known about whether causal beliefs about obesity are associated with lifestyle behaviors. Study objectives were as follows: 1) to document the prevalence of various causal beliefs about obesity (i.e., genes versus lifestyle behaviors), and 2) to determine the association between obesity causal beliefs and self-reported dietary and physical activity behaviors.
\end{abstract}

Methods: The study data were drawn from the 2007 Health Information National Trends Survey (HINTS). A total of 3,534 individuals were included in the present study.

Results: Overall, $72 \%$ of respondents endorsed the belief that lifestyle behaviors have 'a lot' to do with causing obesity, whereas 19\% indicated that inheritance has 'a lot' to do with causing obesity. Multinomial logistic regression analyses indicated that the belief that obesity is inherited was associated with lower reported levels of physical activity ( $\mathrm{OR}=0.87,95 \% \mathrm{Cl}: 0.77-0.99)$ and fruit and vegetable consumption ( $\mathrm{OR}=0.87,95 \% \mathrm{Cl}: 0.76-0.99$ ). In contrast, the belief that obesity is caused by lifestyle behaviors was associated with greater reported levels of physical activity $(\mathrm{OR}=1.29,95 \% \mathrm{Cl}: 1.03-1.62)$, but was not associated with fruit and vegetable intake $(\mathrm{OR}=1.07$, 95\% Cl: 0.90-1.28).

Conclusions: Causal beliefs about obesity are associated with some lifestyle behaviors. Additional research is needed to determine whether promoting awareness of the genetic determinants of obesity will decrease the extent to which individuals will engage in the lifestyle behaviors essential to healthy weight management.

\section{Introduction}

The causes of obesity are multifactorial [1]. Recent evidence has begun to shed light on the genetic contributions to obesity [2]. In the 2005 update of the human obesity gene map, 127 candidate genes for obesity were reported, 22 of which were replicated with multiple populations [3]. The majority of rare monogenic or single-gene disorders related to obesity appear to function via the regulation of appetite and impairment of satiety rather than the regulation of metabolism $[2,4,5]$. Common obesity, however, is mostly polygenic and due to the contribution of multiple genes and genetic variants.

\footnotetext{
* Correspondence: clwang@bu.edu

'Boston University School of Public Health, Boston MA, USA
}

Advances in obesity genetics, as well as the genetics of common diseases, has led to a proliferation of direct-toconsumer marketing of genetic tests that enable the identification of one's genetic risk for these conditions. It has been argued that such testing is premature, given the state of the science, and concerns have been raised about the clinical utility of this type of risk information [6-8]. Currently, it is unknown whether providing individuals with information about the genetic determinants of obesity will motivate or discourage weight management behaviors. Researchers have postulated that the provision of genetic information will influence both the cognitive representations or beliefs that people hold about the causes of a disease, as well as their beliefs about the solutions to reducing risk for disease $[9,10]$. Consequently, genetic risk information for obesity could have negative

\section{() Biomed Central}


implications if providing feedback increased people's beliefs about the role of genetics in obesity, but decreased their beliefs about the efficacy and importance of lifestyle behaviors to manage obesity risk. Underlying this notion is the possibility that communicating the genetic risks of obesity might inadvertently serve to reinforce genetically deterministic thinking, which may reduce individuals' engagement in lifestyle behaviors important in maintaining a healthy weight.

As a first step to understanding the possible implications of communicating obesity-related genetic information, this study was undertaken with two main objectives. First, we set out to document the prevalence and correlates of causal beliefs about obesity (i.e., genes versus lifestyle behaviors) in a population-based sample in the United States. Second, we sought to determine the association between obesity causal beliefs and selfreported dietary and physical activity behaviors. The results of this study can shed light on whether obesity causal beliefs might function as a potential mechanism by which the provision of information about the genetic determinants of obesity influences behaviors important in healthy weight management.

\section{Methods and Procedures Procedure}

The study data were drawn from the 2007 Health Information National Trends Survey (HINTS), a national probability survey of health information among U.S. adults conducted by the National Cancer Institute. Participants in the 2007 HINTS were recruited via random digit dialing or a mailing sent to a random sample of U.S. addresses. Participants completed a one-time telephone or paper and pencil survey. Some survey questions differed between the two modes of administration. For the purposes of the current study, we only used data from the mailed paper and pencil survey, as it utilized a two-item cups measure of fruit and vegetable intake that may have greater validity than the two-item servings measure used in the telephone survey (Amy Yaroch, PhD, personal communication, March 2009). The household response rate to the mailed survey was $44.0 \%$ and the within-household response rate was 77.4\%. The 2007 HINTS utilized a cross-sectional, complex sample survey design, data weighting, and jackknife variance estimation. Further information about the HINTS is available elsewhere [11].

\section{Participants}

A total of 7,674 individuals were recruited to the 2007 HINTS, 3,582 of whom completed the survey via mail. We excluded 48 individuals who were missing data for both of the obesity causal belief items, leaving an available sample size of $N=3,534$.

\section{Measures}

\section{Demographics}

Participants indicated their sex, age, race/ethnicity, and level of education. They also reported their height and weight from which we calculated body mass index (BMI) and categorized individuals as being not overweight/obese, overweight, or obese [12].

\section{Obesity causal beliefs}

Participants answered two questions about the causes of obesity: "To what extent do you believe that obesity is inherited?"; and "To what extent do you believe that obesity is caused by overeating and not exercising?". Each item was answered on a 4-point Likert-type scale from not at all to a lot. The correlation between the items was very low $(r=-.05, p=.002)$, justifying their separate examination in the analyses. Responses to the second question were strongly negatively skewed, with $72.4 \%$ of participants answering a lot. Thus, we dichotomized responses to this question to denote individuals who answered a lot versus those who did not.

\section{Physical activity}

Participants indicated how often each week, and for how long, they engage in physical activity or exercise of at least moderate intensity, which was defined as activities that make you breathe somewhat harder than normal (e.g., brisk walking, cycling at a regular pace, heavy gardening). Based on national guidelines [13], we categorized individuals into three groups according to their total amount of weekly activity of at least moderate intensity: (a) sedentary - no weekly activity; (b) insufficient activity - engage in some activity but less than 150 minutes per week; (c) met guidelines - engage in at least 150 minutes of activity per week.

\section{Fruit and vegetable intake}

Participants read examples of the amount of fruits and vegetables that count as 1 cup (e.g., 1 small apple, 8 large strawberries, 12 baby carrots, 1 medium potato). Using 7 response options from none to 4 cups or more, they then indicated approximately how many cups of fruit and how many cups of vegetables they consume each day. We summed responses for the two items to create an index of daily fruit/vegetable intake (with higher scores representing higher intake).

\section{Statistical Analysis}

Initial regression analyses were conducted to examine demographic correlates of the two obesity causal belief items. In a multiple linear regression analysis, the demographic characteristics (sex, age, race/ethnicity, education level, and BMI) were included as independent variables with the inherited causal belief item as the dependent variable. In a multiple logistic regression analysis, the demographic characteristics were included as independent variables with the lifestyle obesity causal 
belief item (i.e., obesity is due to overeating and not exercising) as the dichotomous dependent variable. Next, we conducted two multinomial logistic regression analyses to examine correlates of physical activity and fruit/vegetable intake. In each analysis, the independent variables were the demographic and obesity causal belief items and the ordinal dependent variable was physical activity or fruit/vegetable intake. All statistical analyses were conducted using SUDAAN software (version 9.0.1; Research Triangle Institute, Research Triangle Park, NC). All percentages reported in the Results section are weighted and all sample sizes are unweighted. A cutoff of $p<.05$ was used to determine statistical significance for all analyses.

\section{Results}

\section{Sample Characteristics}

Descriptive statistics regarding the demographic and causal belief items are shown in Table 1. There was considerable variability with regard to the age, race/ethnicity, and level of education of the study participants. More than a quarter of the participants were obese and a third were overweight. Less than a quarter of participants indicated that inheritance has 'a lot' to do with causing obesity. Over two-thirds of participants indicated that they believe obesity is caused 'a lot' by overeating and not exercising.

\section{Correlates of Obesity Causal Beliefs}

The results of multiple regression analyses examining correlates of obesity causal beliefs are shown in Table 2 . Age, race/ethnicity, and education were not associated with the belief that obesity is inherited. There was a marginally significant association $(p=.056)$ suggesting that women were more likely to believe that obesity is inherited than men. Individuals who were obese more strongly endorsed the belief that obesity is inherited than individuals who were not overweight or obese.

Sex, age, and BMI were not associated with the belief that obesity is caused by overeating and not exercising. Individuals with a college degree were more likely to believe that obesity is caused by overeating and not exercising compared to those with a high school education. Compared to non-Hispanic white individuals, Hispanic individuals were more likely to believe that obesity is caused by overeating and not exercising and blacks were less likely to hold that belief.

\section{Correlates of Physical Activity and Fruit/Vegetable Intake} Just over a third of the participants (37.9\%) were categorized as sedentary, $26.8 \%$ engaged in insufficient activity, and $35.3 \%$ met physical activity guidelines. Table 3 shows the results of the multinomial regression analysis examining correlates of physical activity. Demographic factors associated with engaging in a lower amount of physical activity included being female, older, having a lower education level, and being obese. Additionally, the belief that obesity is inherited was associated with lower reported levels of physical activity. The belief that obesity is caused by overeating and not exercising was associated with greater reported levels of physical activity. We also conducted exploratory analyses to examine whether there was a significant interaction between body mass index and each of the causal beliefs items. The presence of a statistically significant interaction would indicate that the association between the causal belief and physical activity varied according to body mass index. However, neither of the two interaction terms was statistically significant ( $p$ s > .309).

Participants reported consuming a median of 3-5 cups of fruits and vegetables per day. As shown in Table 3, demographic factors associated with a lower fruit and vegetable intake included being male, younger, having a lower education level, and being obese. The belief that obesity is inherited was associated with lower fruit and vegetable consumption. The belief that obesity is caused by overeating and not exercising was not associated with fruit and vegetable intake. We again conducted exploratory analyses to examine whether there was a significant interaction between body mass index and each of the causal beliefs items. Neither of the two interaction terms was statistically significant $(p s>.365)$.

\section{Discussion}

To our knowledge, this is one of the first studies to examine whether causal beliefs about obesity are associated with health behaviors important in weight management. This study contributes to the growing literature examining causal beliefs about obesity among individuals in the general population $[14,15]$ and highlights how public health messages about the genetic etiology of obesity may influence obesity-related causal beliefs, which in turn, may influence health behaviors.

Overall, the majority of individuals in the current study believed that overeating and inactivity contribute to obesity. Substantially fewer endorsed the notion that obesity is caused by inheritance and genetics. This finding is opposite to what is commonly reported by obese individuals [16] and suggests that non-obese individuals are more likely to ascribe to the belief that obesity can be controlled via lifestyle behaviors. Within the present study, greater BMI was positively associated with beliefs about the role of inheritance, suggesting that beliefs about the role of inheritance vary significantly between obese and non-obese individuals. Similar to findings among obese individuals, there was some evidence in the present study ( $p=.056)$ that beliefs about the role 
Table 1 Descriptive Statistics for the Demographic Characteristics and Obesity Causal Belief Items

\begin{tabular}{|c|c|c|}
\hline & $\begin{array}{r}\text { Unweighted } \\
\text { Sample Size }(n)\end{array}$ & $\begin{array}{l}\text { Weighted } \\
\text { Sample \% }\end{array}$ \\
\hline \multicolumn{3}{|l|}{ Sex } \\
\hline Male & 1372 & 48.9 \\
\hline Female & 2159 & 51.1 \\
\hline Missing $(n)$ & 3 & \\
\hline \multicolumn{3}{|l|}{ Age (years) $(M=45.6)$} \\
\hline $18-39$ & 860 & 39.8 \\
\hline $40-49$ & 644 & 20.4 \\
\hline $50-59$ & 809 & 17.0 \\
\hline $60-69$ & 603 & 10.8 \\
\hline$\geq 70$ & 573 & 12.0 \\
\hline Missing $(n)$ & 45 & \\
\hline \multicolumn{3}{|l|}{ Race/ethnicity } \\
\hline Hispanic & 309 & 12.5 \\
\hline Non-Hispanic white & 2460 & 69.5 \\
\hline Non-Hispanic black & 431 & 11.5 \\
\hline Non-Hispanic other & 225 & 6.5 \\
\hline Missing $(n)$ & 109 & \\
\hline \multicolumn{3}{|l|}{ Education } \\
\hline Less than high school & 306 & 13.8 \\
\hline High school graduate & 805 & 24.4 \\
\hline Some college & 1130 & 36.8 \\
\hline College graduate & 1269 & 25.0 \\
\hline Missing $(n)$ & 24 & \\
\hline \multicolumn{3}{|l|}{ Body mass index $(M=27.6)$} \\
\hline $\begin{array}{l}\text { Not overweight/obese }(\mathrm{BMI}< \\
25 \mathrm{~kg} / \mathrm{m}^{2} \text { ) }\end{array}$ & 1286 & 37.3 \\
\hline Overweight (BMI 25-29.9 kg/m²) & 1168 & 34.0 \\
\hline Obese (BMI $\geq 30 \mathrm{~kg} / \mathrm{m}^{2}$ ) & 1018 & 28.7 \\
\hline Missing $(n)$ & 62 & \\
\hline \multicolumn{3}{|l|}{ Belief that obesity is inherited } \\
\hline Not at all & 334 & 9.7 \\
\hline A little & 890 & 25.2 \\
\hline Some & 1670 & 46.4 \\
\hline A lot & 627 & 18.6 \\
\hline Missing $(n)$ & 13 & \\
\hline
\end{tabular}

Belief that obesity is caused by overeating and not exercising

Not at all

A little $\quad 30$

Some $\quad 132$

A lot 817

Missing (n) 2542

Note. $N=3,534$. Data are from respondents who completed a paper and pencil mailed survey for the 2007 Health Information National Trends Survey (HINTS). of inheritance in obesity may be more common among women than men [16].

This study provides evidence of the association between obesity causal beliefs and health behaviors essential in weight management. Beliefs about the role of inheritance in obesity were negatively associated with both self-reported physical activity and dietary intake. Beliefs about the role of lifestyle in obesity correlated in the opposite direction with physical activity, providing some support for the importance of emphasizing the role of health behaviors in the prevention and management of obesity. The lack of association between lifestyle beliefs and self-reported diet may be, in part, due to how the former was assessed. The belief about lifestyle as a cause of obesity was assessed with regard to "overeating and not exercising", whereas diet was assessed in terms of fruit and vegetable intake as opposed to behaviors related to overeating (e.g., caloric intake). Other research assessing causal beliefs in the context of cancer suggests that people distinguish between various causes, highlighting the importance of specificity in the measurement of causal beliefs [17].

Identifying the relationship between causal beliefs about obesity and health behaviors is important in order to understand the potential implications of communicating genetic risk information. More research is necessary to shed light on the mechanism by which causal beliefs might influence health behaviors. For example, beliefs about the heritability of obesity may correspond to greater fatalistic perceptions and lower perceptions of disease controllability. Available qualitative, hypothetical, and clinical studies have both supported [18-22] and refuted [16,23-25] this possibility. It has also been suggested that the provision of genetic risk information may influence beliefs about the efficacy of various responses or solutions, such as a healthy diet, to reduce disease risk [26-29]. Additional research, guided by strong theoretical foundations (e.g., attribution theory, self-regulation theory) will contribute greatly to our understanding of the impact of genetic risk information on behavioral outcomes $[9,21]$.

Endorsement of the heritability of obesity may reflect either a sense of genetic determinism (i.e., disease is inevitable) or a sense of genetic susceptibility (i.e., increased disease risk that lifestyle changes can counteract). In the current study, $73 \%$ of individuals who indicated that inherited factors have "a lot" to do with causing obesity also said that it is caused "a lot" by overeating and lack of exercise. Prior research suggests that people have a complex understanding of the role of genetics in common diseases and attribute these diseases to both genes and behavior [15,30-32]. Future research is needed to further explore potential attribution profiles among those who endorse genetics or inheritance as a 
Table 2 Results of Multiple Regression Analyses Examining Correlates of Obesity Causal Beliefs

\begin{tabular}{|c|c|c|c|c|}
\hline & \multicolumn{2}{|c|}{ Belief that Obesity is Inherited } & \multicolumn{2}{|c|}{ Belief that Obesity is Caused by Overeating and Not Exercising } \\
\hline & $b(95 \% \mathrm{Cl})$ & $p$ value ${ }^{a}$ & OR $(95 \% \mathrm{Cl})$ & $p$ value $^{\mathrm{a}}$ \\
\hline Sex & $-0.09(-0.18,0.00)$ & .056 & $0.90(0.75,1.08)$ & 0.247 \\
\hline Age (years) & & .098 & & 0.153 \\
\hline $18-39$ & Ref & & Ref & \\
\hline $40-49$ & $0.05(-0.06,0.16)$ & .385 & $0.78(0.57,1.07)$ & \\
\hline $50-59$ & $0.04(-0.07,0.15)$ & .486 & $0.83(0.61,1.13)$ & \\
\hline $60-69$ & $-0.03(-0.14,0.09)$ & 62 & $1.03(0.76,1.39)$ & \\
\hline$\geq 70$ & $-0.13(-0.28,0.02)$ & .09 & $0.99(0.69,1.42)$ & \\
\hline Race/ethnicity & & .752 & & 0.002 \\
\hline Hispanic & $-0.01(-0.22,0.20)$ & .91 & $1.61(1.02,2.54)$ & \\
\hline Non-Hispanic white & Ref & & Ref & \\
\hline Non-Hispanic black & $0.01(-0.12,0.14)$ & .887 & $0.65(0.46,0.91)$ & \\
\hline Non-Hispanic other & $0.12(-0.10,0.34)$ & .292 & $1.18(0.76,1.83)$ & \\
\hline Education & & .182 & & 0.019 \\
\hline Less than high school & $0.07(-0.09,0.23)$ & .373 & $0.96(0.60,1.54)$ & \\
\hline High school graduate & $0.10(0.00,0.20)$ & .056 & $0.67(0.51,0.88)$ & \\
\hline Some college & $0.08(-0.01,0.17)$ & .071 & $0.98(0.76,1.24)$ & \\
\hline College graduate & Ref & & Ref & \\
\hline Body mass index & & .007 & & 0.404 \\
\hline Not overweight/obese & Ref & & Ref & \\
\hline Overweight & $0.05(-0.05,0.16)$ & .334 & $1.17(0.92,1.50)$ & \\
\hline Obese & $0.19(0.07,0.31)$ & .002 & $1.15(0.85,1.56)$ & \\
\hline
\end{tabular}

Note. Data are from respondents who completed a paper and pencil mailed survey for the 2007 Health Information National Trends Survey (HINTS).

a The $p$ values adjacent to each variable name (sex, age, race/ethnicity, and so on) represent the association between the variable and the obesity causal belief item.

cause of obesity, since they may be associated with different behavioral outcomes.

The study findings suggest that causal beliefs and attributions are important to consider when communicating messages about disease risk factors. Notably, casual beliefs appear to vary across diseases $[27,30,32]$. Less than a quarter of individuals in this study believed that inheritance was important in obesity causation. Greater endorsement of the causal role of heredity has been reported for other diseases, such as breast and colorectal cancer, wherein over $75 \%$ of women believe it to be a cause [17]. The extent to which common diseases are viewed as "genetic" or "heritable" in nature appears to be illness-specific and this may have implications for how genetic risk information is processed, understood, and acted upon by individuals $[9,33]$.

Research is needed to determine how prior casual beliefs and attributions influence individual responses to genetic risk messages. Related, studies are also needed on the extent to which causal beliefs can be modified. Initial evidence suggests that beliefs about the role of genetics in obesity can be altered $[27,34,35]$. Less is known about the implications of modifying causal beliefs and whether changing beliefs about the role of inheritance/heredity in obesity can occur without negatively influencing motivation to engage in weight management behaviors.

This study had several limitations. As part of a national population-based survey, we were limited by the use of single items to assess causal beliefs. Although this has been a common approach in prior research, we acknowledge the inherent limitations of single-item measures. Further research is needed on the measurement of disease causal beliefs [36]. In addition, assessments of physical activity and diet were based on self-reports, which may result in overestimates of actual behavior, but would not be expected to influence the association between beliefs and behaviors. Physical activity and fruit and vegetable intake were assessed using brief measures, although there is evidence for the acceptable psychometric properties of such measures [37-42]. Fruit and vegetable intake are the only dietary behaviors assessed in the 2007 HINTS. Future research should examine the association 
Table 3 Results of Multiple Multinomial Logistic Regression Analyses Examining Correlates of Physical Activity and Fruit and Vegetable Intake

\begin{tabular}{|c|c|c|c|c|}
\hline & \multicolumn{2}{|c|}{ Physical Activity } & \multicolumn{2}{|c|}{ Fruit and Vegetable Intake } \\
\hline & OR $(95 \% \mathrm{Cl})$ & $p$ value $^{a}$ & OR $(95 \% \mathrm{Cl})$ & $p$ value $^{\mathrm{a}}$ \\
\hline Sex & $1.31(1.08,1.59)$ & .006 & $0.71(0.58,0.85)$ & $<.001$ \\
\hline Age (years) & & .009 & & .039 \\
\hline $18-39$ & Ref & & Ref & \\
\hline $40-49$ & $0.81(0.62,1.06)$ & & $0.83(0.64,1.06)$ & \\
\hline $50-59$ & $1.01(0.77,1.31)$ & & $0.96(0.76,1.20)$ & \\
\hline $60-69$ & $0.73(0.56,0.96)$ & & $1.12(0.88,1.42)$ & \\
\hline$\geq 70$ & $0.63(0.45,0.89)$ & & $1.21(0.93,1.57)$ & \\
\hline Race/ethnicity & & .113 & & .912 \\
\hline Hispanic & $0.72(0.47,1.11)$ & & $0.98(0.63,1.52)$ & \\
\hline Non-Hispanic white & Ref & & Ref & \\
\hline Non-Hispanic black & $0.74(0.53,1.03)$ & & $1.09(0.80,1.50)$ & \\
\hline Non-Hispanic other & $0.79(0.53,1.18)$ & & $1.12(0.68,1.87)$ & \\
\hline Education & & $<.001$ & & $<.001$ \\
\hline Less than high school & $0.39(0.24,0.62)$ & & $0.39(0.24,0.62)$ & \\
\hline High school graduate & $0.45(0.35,0.56)$ & & $0.45(0.35,0.56)$ & \\
\hline Some college & $0.84(0.67,1.05)$ & & $0.84(0.67,1.05)$ & \\
\hline College graduate & Ref & & Ref & \\
\hline Body mass index & & $<.001$ & & .016 \\
\hline Not overweight/obese & Ref & & Ref & \\
\hline Overweight & $0.99(0.75,1.30)$ & & $0.88(0.70,1.10)$ & \\
\hline Obese & $0.50(0.39,0.64)$ & & $0.73(0.59,0.91)$ & \\
\hline Belief that obesity is inherited & $0.87(0.77,0.99)$ & .027 & $0.87(0.76,0.99)$ & .028 \\
\hline $\begin{array}{l}\text { Belief that obesity is caused by overeating } \\
\text { and not exercising }\end{array}$ & $1.29(1.03,1.62)$ & .025 & $1.07(0.90,1.28)$ & .432 \\
\hline
\end{tabular}

Note. Data are from respondents who completed a paper and pencil mailed survey for the 2007 Health Information National Trends Survey (HINTS).

${ }^{a}$ The $p$ values adjacent to each variable name (sex, age, race/ethnicity, and so on) represent the association between the variable and physical activity or fruit and vegetable intake.

between obesity causal beliefs and other dietary behaviors (such as caloric intake and portion sizes). Finally, this study was cross-sectional in nature and inferences about causality cannot be made. Longitudinal studies are critically needed to determine the impact of modifying causal beliefs on behavioral outcomes of interest.

\section{Conclusions}

Beliefs about the causes of obesity are associated with physical activity and dietary behaviors of individuals in the general population. Additional research is needed to determine whether promoting awareness of the genetic determinants of obesity will decrease the extent to which individuals will engage in the lifestyle behaviors essential to healthy weight management.

\section{Acknowledgements}

Dr. Wang (K07 CA131103) and Dr. Coups (K07 CA133100) are supported by career development awards from the National Cancer Institute.

\section{Author details}

${ }^{1}$ Boston University School of Public Health, Boston MA, USA. ${ }^{2}$ The Cancer Institute of New Jersey, New Brunswick NJ, USA. ${ }^{3}$ UMDNJ-Robert Wood Johnson Medical School, New Brunswick NJ, USA.

\section{Authors' contributions}

CW conceived of the study, participated in the design of the study, and drafted the manuscript. EJC participated in the design of the study, performed the statistical analysis, and drafted the manuscript. Both authors reviewed, revised, and approved the final manuscript.

\section{Competing interests}

The authors declare that they have no competing interests.

Received: 12 October 2009 Accepted: 3 March 2010 Published: 3 March 2010 


\section{References}

1. Gene-Nutrition and Gene-Physical Activity Interactions in the Etiology of Obesity Workshop. Obesity (Silver Spring) 2008, 16(Suppl 3):S1-96.

2. Walley AJ, Asher JE, Froguel P: The genetic contribution to non-syndromic human obesity. Nat Rev Genet 2009, 10:431-442

3. Rankinen T, Zuberi A, Chagnon YC, Weisnagel SJ, Argyropoulos G, Walts B, Perusse L, Bouchard C: The human obesity gene map: the 2005 update. Obesity (Silver Spring) 2006, 14:529-644.

4. Farooqi IS, O'Rahilly S: Genetic factors in human obesity. Obes Rev 2007, 8(Suppl 1):37-40

5. Newell A, Zlot A, Silvey K, Arail K: Addressing the obesity epidemic: a genomics perspective. Prev Chronic Dis 2007, 4:A31.

6. Kolor K, Liu T, St Pierre J, Khoury MJ: Health care provider and consumer awareness, perceptions, and use of direct-to-consumer personal genomic tests, United States, 2008. Genet Med 2009, 11:595.

7. Henrikson NB, Bowen $D$, Burke W: Does genomic risk information motivate people to change their behavior?. Genome Med 2009, 1:37.

8. Kraft $P$, Hunter DJ: Genetic risk prediction-are we there yet?. N Engl J Med 2009, 360:1701-1703.

9. Marteau TM, Weinman J: Self-regulation and the behavioural response to DNA risk information: A theoretical analysis and framework for future research. Soc Sci Med 2006, 62:1360-1368.

10. Marteau TM, Senior V: Illness representations after the Human Genome Project: The perceived role of genes in causing illness. Perceptions of Health \& IIIness Amsterdam: Harwood Academic PublishersPetrie KJ, Weinman JA 1997, 241-266

11. Cantor DCK, Crystal-Mansour S, Davis T, Dipko S, Sigman R: Health Information National Trends Survey (HINTS): Final Report.http://hints. cancer.gov/dataset.jsp.

12. National Heart Lung and Blood Institute: Clinical guidelines on the identification, evaluation, and treatment of overweight and obesity in adults [NIH Publication No. 98-4083]. National Institutes of Health 1998.

13. Haskell WL, Lee IM, Pate RR, Powell KE, Blair SN, Franklin BA, Macera CA, Heath GW, Thompson PD, Bauman A: Physical activity and public health: updated recommendation for adults from the American College of Sports Medicine and the American Heart Association. Circulation 2007 116:1081-1093.

14. Ogden J, Flanagan Z: Beliefs about the causes and solutions to obesity: a comparison of GPs and lay people. Patient Educ Couns 2008, 71:72-78.

15. Molster C, Charles T, Samanek A, O'Leary P: Australian study on public knowledge of human genetics and health. Public Health Genomics 2009, 12:84-91.

16. Hilbert A, Dierk JM, Conradt M, Schlumberger P, Hinney A, Hebebrand J, Rief W: Causal attributions of obese men and women in genetic testing: Implications of genetic/biological attributions. Psychol Health 2009.

17. Wang C, Miller SM, Egleston BL, Hay JL, Weinberg D: Beliefs about the causes of breast and colorectal cancer among women in the general population. Cancer Causes Control 2010, 21:99-207.

18. Senior V, Marteau TM, Peters TJ: Will genetic testing for predisposition for disease result in fatalism? A qualitative study of parents responses to neonatal screening for familial hypercholesterolaemia. Soc Sci Med 1999 48:1857-1860.

19. Senior V, Marteau TM, Weinman J: Impact of genetic testing on causal models of heart disease and arthritis: An analogue study. Psychol Health 2000, 14:1077-1088.

20. Frosch DL, Mello P, Lerman C: Behavioral consequences of testing for obesity risk. Cancer Epidemio, Biomarkers Prev 2005, 14:1485-1489.

21. Jeong SH: Effects of news about genetics and obesity on controllability attribution and helping behavior. Health Commun 2007, 22:221-228.

22. Walter FM, Emery J: Perceptions of family history across common diseases: a qualitative study in primary care. Family Practice 2006, 23:472-480.

23. Wright AJ, Weinman J, Marteau TM: The impact of learning of a genetic predisposition to nicotine dependence: an analogue study. Tob Control 2003, 12:227-230.

24. Pijl M, Timmermans DR, Claassen L, Janssens AC, Nijpels G, Dekker JM, Marteau TM, Henneman L: Impact of communicating familial risk of diabetes on illness perceptions and self-reported behavioral outcomes: a randomized controlled trial. Diabetes Care 2009, 32:597-599.

25. Marteau T, Senior V, Humphries SE, Bobrow M, Cranston T, Crook MA Day L, Fernandez M, Horne R, Iversen A, et al: Psychological impact of genetic testing for familial hypercholesterolemia within a previously aware population: A randomized controlled trial. Am J Med Genet 2004, 128A:285-293

26. Senior $V$, Marteau TM: Causal attributions for raised cholesterol and perceptions of effective risk-reduction: Self-regulation strategies for an increased risk of coronary heart disease. Psychol Health 2007, 22:699-717.

27. Ogden J, Jubb A: How consistent are beliefs about the causes and solutions to illness? An experimental study. Psychol Health Med 2008, 13:505-515.

28. Sanderson SC, O'Neill SC, White DB, Bepler G, Bastian L, Lipkus IM McBride CM: Responses to online GSTM1 genetic test results among smokers related to patients with lung cancer: a pilot study. Cancer Epidemiol Biomarkers Prev 2009, 18:1953-1961.

29. Wang C, Miller SM, Egleston BL, Weinberg D: Genetic vs. non-genetic causal attributions for breast cancer and their association with health behaviors. Ann Behav Med 2009, 37:S49.

30. McBride CM, Alford SH, Reid RJ, Larson EB, Baxevanis AD, Brody LC: Characteristics of users of online personalized genomic risk assessments: Implications for physician-patient interactions. Genet Med 2009, 11(8):582-7.

31. Bates BB, Templeton A, Achter PJ, Harris TM, Condit CM: What does "a gene for heart disease" mean? A focus group study of public understandings of genetic risk factors. Am J Med Genet 2003, 119A:156-161

32. Parrott RL, Silk KJ, Condit C: Diversity in lay perceptions of the sources of human traits: genes, environments, and personal behaviors. Socl Sci Med 2003, 56:1099-1109.

33. Leventhal $H$, Brissette I, Leventhal EA: The common-sense model of selfregulation of health and illness. The self-regulation of health and illness behavior NY: RoutledgeCameron LD, Leventhal H 2003, 42-65.

34. Rief W, Conradt M, Dierk JM, Rauh E, Schlumberger P, Hinney A, Hebebrand J: Is information on genetic determinants of obesity helpful or harmful for obese people?-A randomized clinical trial. J Gen Intern Med 2007, 22:1553-1559.

35. Sanderson SC, Persky S, Michie S: Psychological and behavioral responses to genetic test results indicating increased risk of obesity: Does the causal pathway from gene to obesity matter?. Public Health Genomics 2009, 13:34-42.

36. French DP, Marteau TM, Senior V, Weinman J: How valid are measures of beliefs about the causes of illness? The example of myocardial infarction. Psychol Health 2005, 20:615-635.

37. Brown WJ, Trost SG, Bauman A, Mummery K, Owen N: Test-retest reliability of four physical activity measures used in population surveys. J Sci Med Sport 2004, 7:205-215.

38. Cappuccio FP, Rink E, Perkins-Porras L, McKay C, Hilton S, Steptoe A Estimation of fruit and vegetable intake using a two-item dietary questionnaire: a potential tool for primary health care workers. Nutr Metab Cardiovasc Dis 2003, 13:12-19.

39. Kim DJ, Holowaty EJ: Brief, validated survey instruments for the measurement of fruit and vegetable intakes in adults: a review. Prev Med 2003, 36:440-447.

40. Nelson DE, Holtzman D, Bolen J, Stanwyck CA, Mack KA: Reliability and validity of measures from the Behavioral Risk Factor Surveillance System (BRFSS). Soz Praventivmed 2001, 46(Suppl 1):S3-42.

41. Sallis JF, Saelens BE: Assessment of physical activity by self-report: status, limitations, and future directions. Res Q Exerc Sport 2000, 71:S1-14.

42. Yore MM, Ham SA, Ainsworth BE, Kruger J, Reis JP, Kohl HW, Macera CA Reliability and validity of the instrument used in BRFSS to assess physical activity. Med Sci Sports Exerc 2007, 39:1267-1274.

doi:10.1186/1479-5868-7-19

Cite this article as: Wang and Coups: Causal beliefs about obesity and associated health behaviors: results from a population-based survey. International Journal of Behavioral Nutrition and Physical Activity 2010 7:19. 